\title{
INNOVATIVE CHANGES FOR REACHING SUSTAINABILITY IN UNIVERSITIES
}

\author{
Deneş, Călin ${ }^{1}$ and Grecu, Valentin ${ }^{2}$ \\ 1 "Lucian Blaga" University of Sibiu, Romania, calin.denes@ulbsibiu.ro \\ 2 “Lucian Blaga” University of Sibiu, Romania, valentin.grecu@ulbsibiu.ro
}

\begin{abstract}
This paper presents an original approach to the changes required for the transformation of universities in sustainable universities. The focus is on the innovative approach of all activities and relationships of the university: teaching, scientific research and other services offered by the university, the relations of the university with the communities where it operates, inter-university relations, relations with business environment, etc. Based on the experience and information gathered by the authors in the strategic project "Improving University Management", it is proposed a better, more efficient and more effective way of using the resources of universities, thus sharing the resources within the university and with others partners. Shared resources can belong not only to universities but also to their other collaborating organizations interested in the general progress of the society. This can become reality only if the universities will realize that by working together they can achieve higher performance rather than by simply competing with each other, approach which is not excluded but otherwise addressed.
\end{abstract}

KEY WORDS: sustainable universities, innovation, resource sharing.

\section{INTRODUCTION}

Society can't develop in any way. Sustainable development is, for now, the only rational way acceptable to its development. Such a society can't be built anyway. Education is the only instrument for shaping such a society. School, in general and universities, in particular, have a decisive role in reaching the sustainable society. Universities can be a catalyst for transformation towards a sustainable society. For this, first of all universities have to become sustainable.

Universities need to allocate resources wisely to become sustainable and to give students life experience in a sustainable environment. They must be the catalyst for the necessary changes in the whole society and their students are tools that transform the whole society towards sustainable development.

Also, universities need to honor their role and importance held in the communities where they operate and serve. They should not be isolated but rather must integrate as harmoniously into society and contribute decisively to the progress. For that, universities must be adapted to the demands of society and to generate the vision, the desirable changes in the evolution of the entire university and society. Thus, from an educational point of view, public universities must comply with lifelong learning. On the other hand, considering the research plan, the university must be involved in the positive evolution of society. This means that the university should always be innovative.

Nowadays we are constantly confronted with problems that we need to resolve, new situations in which we want to overtake or projects that we want to achieve and we require in a greater or lesser extent our resourcefulness, creativity and ingenuity. But ultimately each of us manages to find original ideas and tricks which - not once - surprise us. These times correspond to moments of creativity, when using our personal resources and inspirations, we organize knowledge and skills in a new way. This provision is growing, and is useful to know its basic mechanisms, to make an assessment of aspirations and to practice continuously.
The issue of sustainable development (sustainability) is increasingly present among the concerns of the international academic community. However, the depth of our unsustainable practices suggests that there was enough progress to move from unsustainable lifestyles to sustainable development. However, as in all relevant and visionary new actions where people are committed, there is always a boiling period required to develop and submit ideas to launch large-scale discussions to refine the concepts to correct and adjust.

This occurs in sustainable development in higher education. Many new educational approaches are tested. Some work in certain places, but have not yet been tested elsewhere, we do not know if they have wider applicability or if they must be adapted to each new cultural, geographical context, etc.

Innovation is the path that helps universities to adapt to the dynamics of the social changes and allows them to meet their important role that they have in assuring the progress of humanity.

There is difference between "is" and "should be" between "real" and "ideal". Innovation processes can be reduced essentially to solving problems. The road between the problem and the solution is based on a starting point barrier, an obstacle. The problem is given by a tension, a difference between "being" and "must be" between "real" and "ideal" and between "truth" and "imaginary desire" [2].

Innovation, trying to propose new elements, hitherto unknown and untried, destabilizes the current system. Even if the objective is to improve the system, destabilizing conflicts with the desire to have everything in place so that innovation will be adopted more often as a result of internal pressure. In almost all cases innovation capacities are overestimated by individuals, organizations and society. Innovative processes can be significantly delayed, sometimes stopped by the emergence of obstacles. An accurate analysis of possible barriers is essential for the success of innovation ideas. 
Innovation requires firstly the identification of new techniques of creativity (individual or group), spontaneous inspiration or ability to make connections being useful in this regard. But creativity does not solve the problem. It only provides a solution to be translated into reality. This requires an entrepreneurial spirit and efforts, often large and difficult. Romanian academician Mihai Drăgănescu shows that while creativity is an almost permanent phenomenon of human nature, creation is rare. Because of this reason, the emergence of new things as results of creativity must be followed by their practical application to solve problems or to achieve progress.

Innovation is designed to introduce new social practice. The issue here is not only about economic or technological success but also industrial, commercial, social and cultural. The process is long, has an interactive and iterative process, involving many more actors with complementary knowledge and often suffers many adaptations before becoming a success [2]. Therefore, the purpose of innovation remains success, progress, the step taken forward, not backward.

\section{A NEW PERSPECTIVE OF UNIVERSITIES' ACTIVITIES AND RELATIONSHIPS}

Higher education institutions must continually improve the impact they have on society, economy and environment. Current belief systems contend that nothing is isolated: student, teacher, institution, curriculum, pedagogy, policy, management system, community, media, culture, etc. Therefore, all intended changes must anticipate systemic effects at different levels and, where possible, to participate in sustainable development and to generate positive effects. Instead of fragmentation, integrative, holistic, approaches should be preferred, that lead to coherent learning experience for teachers, researchers, administrative staff, students and institutions themselves.

At least five main dimensions of any university can be observed: ethos (culturally university) curriculum, strategies and teaching styles, strategies and management styles, links with the community. All these should not be seen separately (this is non-systemic) but in relation to each other, especially when they are to make changes to improve processes, activities and relations.

It is useful to distinguish between a gradual change ("step by step"), where the system elements are changed without taking into account the full effects and systemic change, where the effects of all parties are taken into account from the start. The latter would require assessing over time how much the five dimensions of a university are in harmony or conflict. Gradual changes and systemic characteristics are summarized in Table 1 [3].

Table 1. Characteristics of gradual and systemic changes.

\begin{tabular}{|c|c|}
\hline Gradual changes & Systemic change \\
\hline $\begin{array}{c}\text { - involves changing parts of } \\
\text { a system }\end{array}$ & $\begin{array}{l}\cdot \text { is done taking into account } \\
\text { the effects on the entire system }\end{array}$ \\
\hline $\begin{array}{l}\text { - take little or nothing, into } \\
\text { consideration the system } \\
\text { seen as a whole }\end{array}$ & $\begin{array}{l}\text { - recognizes and anticipates the } \\
\text { necessary qualities }\end{array}$ \\
\hline • are often imposed & $\begin{array}{l}\text { - are made with a purpose, are } \\
\text { based on collaboration and } \\
\text { maximize participation }\end{array}$ \\
\hline - involve less learning & $\begin{array}{l}\text { - monitor and learn from the } \\
\text { effects of change }\end{array}$ \\
\hline - are often short & $\bullet$ are often lengthy \\
\hline - are often short & - are often lengthy \\
\hline
\end{tabular}

Important areas for the implementation and institutionalization of sustainability in a university refers to [1, 3]: vision, mission and objectives, strategic plans and operational plans, budget, campus, student life and residents, policy construction and procurement policies; first year student experience, curriculum revision, partnerships with community, human resources development.

Differentiation between universities is provided rather by how they perform their core activities: education and research (education must be adapted to current needs and research must produce positive, visible outcomes). Dynamic transformation of society must determine universities to provide a different academic environment - to "produce" graduates who are at the same time, responsible people and professionals. This requires changes both in the organization and the people. Change requires clear objectives (clearly defined), time and resources. They have to be made both top-down (for providing resources, facilitating change, and motivating people) and bottom-up (involving everyone, including students). Bottom-up changes must prevail and turn as many into intrapreneurs (people who develop universities from the inside, through initiatives, proposals, commitment, dedication, cooperation, positive and proactive attitude).

Moreover, changes should be aimed at rethinking the role and place of universities in relation to local-regional environment and in relation to the entire society. This can be achieved only by making another type of relationship with all stakeholders. Universities must maintain good relations with the whole working environment (without neglecting the internal environment), taking account of local, regional, national and international aspects.

Strategies developed and implemented by universities must be realistic and address the issues previously mentioned. To be implemented, these changes must be accepted by the academic community. Their assumption can be made by calling the selfinterest - everyone should understand that what is done is also in his/hers interest.

\section{CONSIDERATIONS ON THE SUSTAINABILITY OF ROMANIAN UNIVERSITIES}

In order to answer to the nowadays society needs and to create the conditions for "a relevant and responsive educational system to the specific needs of the economy", the Romanian Executive Unit for Financing Higher Education and Scientific University Research, Development and Innovation (UEFISCDI) initiated the project "Improving University Management" (http://www.management-universitar.ro/), its goal is being to promote updated knowledge, modern techniques and actual management instruments for the higher education institutions across Romania.

The module "Resource Management and Sustainability"within this project, developed and supported by members of the Centre of Competence in University Management - Sibiu, coordinated by "Lucian Blaga" University of Sibiu, aims to be a useful tool for the Romanian universities in their transitions to become strong and sustainable universities. Its content defines the concept of sustainability and shows how a university should evolve to become sustainable.

In training sessions held in the module, which were attended by officials with managerial competences from several Romanian universities, in addition to the plenary presentation of the concepts and issues specific to this module, participants (104 
persons) were asked to take part in some group exercises for analyzing their university, based on structured questionnaires. The analysis of the current situation of Romanian universities in terms of sustainability and identification of necessary changes were the main objectives of the research made in these exercises.

Results [1] showed that in only $22 \%$ of Romanian universities the concept of sustainability is understood correctly and in only $11 \%$ of cases it is included in the vision, mission and objectives of universities (and there are allocated funds for implementation of the concept). Regarding the inclusion of sustainability into the curriculum and research, $31 \%$ of those surveyed responded that their universities teach disciplines which deal (mention) the concept of sustainable development and in $18 \%$ of cases there are programs of study (in the fields of chemistry, economics, public administration, environmental engineering) that include disciplines that approach sustainable development. Only $12 \%$ said that their universities have also master programs dedicated to sustainability. $17 \%$ of respondents said that the universities from which they come there are contracts for research on sustainable development, while $22 \%$ said that departments or research centers on sustainable development already exist or are developing.

In the construction and procurement policies, the majority of respondents $(47 \%)$ said they did not have enough information or refused to answer this question. In $29 \%$ of cases, university campus buildings were insulated with thermal-systems and $12 \%$ have alternative energy installations. Another $12 \%$ said that sustainability is an element to be taken into account when making purchases or builds something in the university, but did not mention anything concrete.

$31 \%$ of respondents said that students are involved in the selective collection and recycling, $23 \%$ claimed that they come from universities that carry out educational projects, organize programs and workshops that include promotion and education for sustainable development. Student circles and research topics related to sustainability are other ways in which students come into contact with it. Also it is revealed that student organizations "timidly start to have concerns" towards sustainable development, or engage in voluntary actions to clean up the various green spaces. $9 \%$ of respondents said that nothing is done to integrate sustainability into student life.

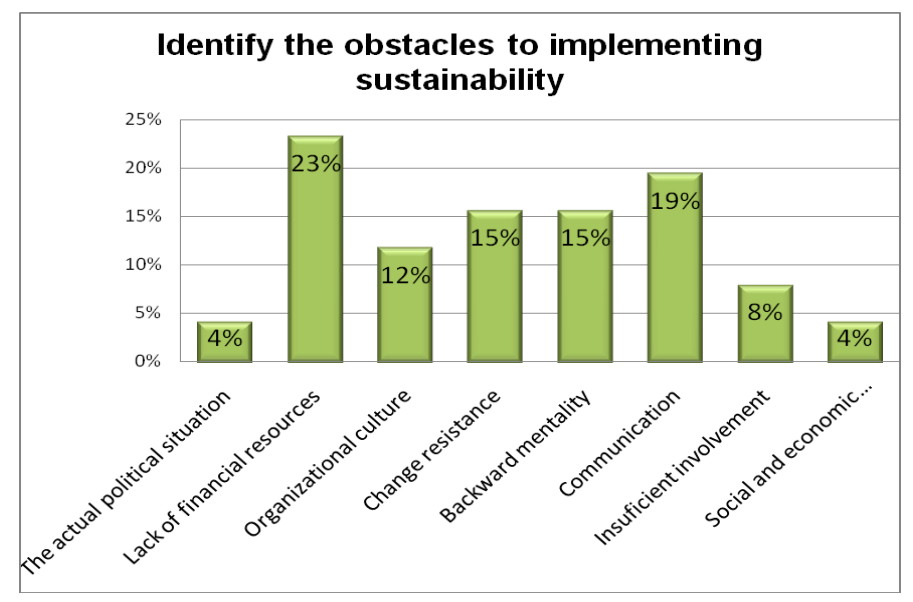

Figure 1. Obstacles to implementing sustainability.

The main barriers identified by respondents, regarding the implementation of sustainable development in higher education are (Fig. 1): lack of financial resources (23\%), poor communication $(19 \%)$, retrograde mentality $(15 \%)$, resistance to change $(15 \%)$; organizational culture of the university
$(12 \%)$, insufficient involvement (8\%). Also, during the debates, the legislative instability in the field of education and the unfavorable or restrictive provisions contained in legal regulations aimed at education were severely criticized.

Asking participants to identify the main changes needed to transform their universities into sustainable universities, the participants identified the following:

- Defining a new vision, mission, strategy and objectives of the university;

- Introduce the concept of sustainable development in as many programs of study;

- Seminars organized by the university to local communities (public awareness), obviously it means a better cooperation between universities and municipalities / county councils (it is an issue that concerns us all);

- Increased transparency of information within the university;

- The emergence of a special department to develop the concept of sustainable development of the university;

- Allocation of specific resources for sustainable development - specific budget and trained personnel;

- Changing the organizational culture - the values and mentality of citizens;

- Taking the best practices, adapting them to their own situation and dissemination in the community;

- Treating the subject as a priority in all curricular subjects.

The results presented above suggest the essence of the required changes of all Romanian universities strategies [4] and highlight the need for adapting the legislation in this field to the current situation and to the trends outlined worldwide. It is expected from the political environment to understand the situation, to apply the necessary corrections and ensure legal stability to facilitate the transformation of the Romanian universities into sustainable universities.

As shown above (see fig. 1), the biggest issue of Romanian universities is underfunding of the educational system. Although the National Education Act, in force, provides for the allocation of at least $6 \%$ of the state and local government budgets to fund education and $1 \%$ of GDP on research, the reality is much different.

To this fact there are added other issues that reduce efficiency and effectiveness of processes and activities of universities. Most facilities (buildings, machinery, equipment, machinery, tools or other equipment) are obsolete and new ones are acquired almost exclusively as a result of the conduct of research projects (grants, research contracts), after completion, they remain in the university heritage. If during the course of projects the usefulness of new features is obvious, after the completion of the projects, in most cases, facilities are not sufficiently used.

In many cases the same equipment items are found in various university departments and financial resources are spent inefficiently and are insufficient anyway.

An overview of equipment needs and existing facilities is necessary for all universities. This involves improving internal communication and a higher dose of interdepartmental collaboration.

Simple steps can be very useful in this regard. An example is determining the load factor, LF, for each item of equipment, the relationship:

$$
\mathrm{LF}=\mathrm{UT} / \mathrm{RT}
$$


where UT is the time of use and RT is the time reference.

LF calculation for each item of equipment (by type of equipment items), centralization of values and communicating them to all staff, together with encouraging interdepartmental collaboration (within faculties and between faculties of universities) ensure efficient use of facilities as certain as and efficiency of investments in equipment.

This approach is convincing and leads to sharing of material facilities. The same reasoning can be used to convince the entire academic community to switch to the sharing of all resources, with obvious benefits especially in the current context of lack of resources due to underfunding of education and scientific research.

Moreover, this trend may lead universities to work together more and to share at least the expensive equipment, which they can purchase and use together, based on well-defined partnerships. The collaboration also can extend the relationship with the external environment of universities (manufacturing companies, research centers, hospitals, cultural institutions, etc.), from local to international level.

Working with the external environment of universities, the community must take various forms, all aimed at mutual benefit and overall progress. An important area of cooperation is that of reducing the gap between labor market needs and the educational offer of universities. Zeroing of the gap is utopian, but its reduction and adaptation of supply and demand in this market is possible through the close collaborator of the stakeholders. In this respect, universities can adapt curricula and content of the taught disciplines to form experts demanded on the labor market, through dialogue with employers and professional organizations of employees. Companies can work with universities to improve students' practical training, by facilitating internship type programs.

To obtain transversal competences, to ensure better use of professional skills, universities can facilitate student involvement in a greater extent in university life and society. In this respect students' associations (local, national, international) and NGOs may have important contributions. Students can receive non-formal educational experiences that significantly improve their preparation and make them do better in the position of the employee or citizen.

Of course, there were presented just a few suggestions and examples, the range of possible activities is much wider as the university has a greater capacity to innovate.

An important aspect related to reaching sustainability in universities is how sustainability can be incorporated into teaching practices [5.]

One of the main factors that affect the student ability to become responsible citizens of a sustainable society is the fact that most teachers are not prepared to offer them these abilities. David Orr recommends that life-long learning opportunities to encourage adult ecological literacy could help teachers guide their students to the sustainability knowledge, skills and values. The question that needs to be asked is whether university teachers are actually working to help students be "both capable and willing to accelerate change to a sustainability society." Taina Kaivola and Mauri Åhlber recognize that "access to information networks and information is not enough. Participation and knowledge building are also required."

The fact that the present culture and organization of most universities establishes a number of barriers to incorporating sustainability is examined by many commentators, including Blewitt, Filho and Sterling [5]. They examined the fact that the organizational cultures of most universities establish a series of barriers. Williams goes further and says "that challenges and barriers are the same or very similar, in all countries".

McKeown lists a number of barriers to re-orienting teacher education towards sustainability, namely:

- lack of awareness that re-orienting to achieve sustainability is essential,

- lack of clarity of what re-orienting entails,

- the limits of the traditional disciplinary boundaries that reward teachers for work within the confines of the discipline only,

- inadequate financial and general resource support for change and

- lack of support for innovative change.

According to Stephen Sterling, (as cited in Williams), "“new ways of learning' need to be transformational and they need to be planned, supported and integrated into all existing educational institutions, if we are to meet our obligations to our children and future societies." Velazquez et al. emphasize that "adequate conditions for the successful implementation of sustainability programmes do not exist". However scholars are increasingly concerned with methods of overcoming these barriers.

Kaivola, Kärpijoki and Saarikko explain that "based on feedback from university pedagogy courses and degree programme revisions, university lecturers attach great importance to the peer support that they get through courses, be it face-to-face or in a web environment. Long-term development work creates partnerships and peer networks thanks to which teachers are more willing to develop and analyze their own working methods".

Based on the presented literature review, our suggestion to overcome the barriers for implementing sustainability into teaching practice is a tool based on the Web 2.0 technologies. Explicitly, a website for disseminating information and best practice and problems sharing, addressed mainly to the teaching community of the universities, but also to the students could ease the transition towards sustainability education.

The importance of the Internet and its tools, which can be used for multiple purposes, consists primarily in promoting organizational learning and finding useful information. Web 2.0 concepts have led to the development and evolution of web-based communities, hosted services and applications, such as social networking sites, records sharing sites, wikis, blogs and folksonomies. Users can own information on a Web 2.0 site and exercise control over that information. These sites may have an "architecture of participation" that encourages users to add value to applications while using them. Web 2.0 tools enable users to produce content, to share it with others, better interaction, socialization of information, syndication, increased usability (improved user experience, democratization and distribution of content).

Some of the advantages of choosing this Web 2.0 tool for overcoming the barriers to implementing sustainability teaching can be [5]:

- teachers can access the website according to their timetable

- $\quad$ reduces travel cost and time to and from school 
- teachers (who in this case will be learners) may have the option to select learning materials that meets their level of knowledge and interest

- teachers can study wherever they have access to a computer and Internet

- $\quad$ self-paced learning modules allow teachers to work at their own pace

- flexibility to join discussions in the bulletin board threaded discussion areas at any hour, or visit with classmates and instructors remotely in chat rooms

- different learning styles are addressed and facilitation of learning occurs through varied activities

- development of computer and Internet skills that are transferable to other facets of teacher's lives

- teachers don't have the feeling that something is being imposed to them. They can access the website on a voluntary basis

- partnerships and collaboration between lecturers can be facilitated by this online tool

By sharing ideas, concepts, tools, experiences learned in different contexts, it is anticipated that we will all learn many things that will help us to help our academic communities and companies to develop the skills to make progress towards sustainable development.

\section{CONCLUSIONS}

The transformation of the society into a sustainable one can be achieved through the decisive contribution of universities. For this to happen, universities must first become sustainable. Then they would provide a good example to all and will offer students life experience for sustainable living. Upon graduation they will implement the learned not only at work but also in families and society.

The sustainable university does not appear instantly and without reason. It is the result of intentional changes made by allocating adequate resources in time, with dedication and consistency. Changes must be made through an innovative approach, mainly of the activities and university relations.
A sustainable university is using the most effective of all available resources. This practice encourages the sharing of resources, both within themselves and in external relations, redefining the relationship between collaboration and competition.

\section{ACKNOWLEDGEMENTS}

This research was conducted in the project POSDRU/88/1.5/S/60370 - "Integrating Romanian research in the context of European research - financed doctoral scholarships".

The papers also capitalizes the experience and information gathered by the authors in the strategic project "Improving University Management”, project POSDRU/2/1.2/S/4.

\section{REFERENCES}

1. Deneş, C., The Sustainability of Romanian Higher Education - University Management Challenge or Chance? Annals of the "Constantin Brâncuşi" University of Târgu Jiu, issue 4/2010, pp 317-327, Academica Brâncuşi Publisher, (2010).

2. Deneş, C. and Grecu, V., Approach to Innovation and Sustainable Development in Higher Education, Proceedings of the 5th International Conference on Manufacturing Science and Education - MSE , Sibiu, pp131-134, (2011).

3. Deneş, C. and Radu, S. Resource Management and Sustainability. Project: Improving University Management, POSDRU/2/1.2/S/4, Project Code: 2679, (2011).

4. Grecu, V. and Denes, C. Sustainability Management in Romania: Challenges and Opportunities, Proceedings of the 19th International Economic Conference: The Persistence of the Global Economic Crisis: Causes, Implications, Solutions, pp 203-212, (2012).

5. Grecu, V. and Denes, C. E-Tools for The Transition TOwards the Sustainable University. Proceedings of the $7^{\text {th }}$ International Conference on Quality Management in Higher Education. Iaşi, pp. 129-138, (2012). 